GASTRIC MOTILITY

\title{
Influence of erythromycin on gastric emptying and meal related symptoms in functional dyspepsia with delayed gastric emptying
}

\author{
J Arts, P Caenepeel, K Verbeke, J Tack
}

Gut 2005;54:455-460. doi: 10.1136/gut.2003.035279

See end of article for authors' affiliations

Correspondence to:

Dr J Tack, Department of Gastroenterology,

University Hospital

Gasthuisberg, Herestraat

49, B-3000 Leuven,

Belgium; Jan.Tack@

med.kuleuven.ac.be

Revised version received 5 August 2004

Accepted for publication

13 August 2004
Background and aims: Although delayed gastric emptying is considered a major pathophysiological mechanism in functional dyspepsia, the efficacy of prokinetic drugs has not been established. Recent studies using macrolide prokinetics were negative but receptor desensitisation may have played a role. The aim of the present study was to evaluate the influence on meal induced symptoms of acutely administered erythromycin in patients with gastroparesis.

Methods: In 20 patients with functional dyspepsia, gastric emptying was studied twice using the ${ }^{14} \mathrm{C}$ octanoic acid and ${ }^{13} \mathrm{C}$ glycin breath test to establish the reproducibility of the test. Breath samples were taken before the meal and at 15 minute intervals for a period of 240 minutes postprandially. At each breath sampling, the patient was asked to grade the intensity (0-3) of six dyspeptic symptoms. Twenty four patients (three men, mean age 43.5 (3) years) with dyspeptic symptoms and delayed gastric emptying were studied twice after pretreatment with saline or erythromycin intravenously.

Results: Meal related symptom severity scores were reproducible. Treatment with erythromycin significantly enhanced solid and liquid gastric emptying $\left(t_{1 / 2} 146(27) \vee 72\right.$ (7) minutes, respectively $(p<0.01)$, and $87(6) \vee 63(5)$ minutes $(p<0.001))$. Only the severity of bloating was significantly improved by erythromycin (23 (3.9) v 14.5 (2.7); $\mathrm{p}<0.01)$; all other symptoms and the cumulative meal related symptom score were not altered by erythromycin.

Conclusions: In a setting where desensitisation played no role, erythromycin enhanced gastric emptying was not associated with a beneficial effect on meal related symptom severity.
$\mathrm{D}$ elayed gastric emptying is considered a major pathophysiological mechanism underlying symptoms in functional dyspepsia and idiopathic gastroparesis..$^{1-12}$ Several studies have investigated the relationship between delayed gastric emptying and symptom pattern and severity. Depending on the study, the percentage of dyspeptic patients with delayed gastric emptying ranges from $25 \%$ to $50 \% .^{1-12}$ Most studies failed to find a relationship between delayed gastric emptying and symptom pattern ${ }^{1-9}$ but recent large scale studies showed that patients with delayed gastric emptying for solids were more likely to report postprandial fullness, nausea, and vomiting. ${ }^{10-12}$

The relationship between symptom pattern and the presence of delayed emptying suggests a possible pathophysiological role for delayed gastric emptying in eliciting dyspeptic symptoms such as fullness, nausea, and vomiting. Patients with delayed gastric emptying are usually treated with gastroprokinetic drugs such as metoclopramide, domperidone, and previously also cisapride, although a relationship between improvement in gastric emptying rate and symptomatic benefit has not been proved. ${ }^{13-16}$ However, the gastroprokinetic effects of these drugs are limited, and the finding of strong gastrokinetic actions for erythromycin, a macrolide antibiotic that acts as a motilin receptor agonist, was met with great enthusiasm. ${ }^{17}$ Several short term studies reported beneficial effects of treatment with erythromycin in gastroparesis. ${ }^{13}{ }^{17-19}$ Different macrolide prokinetics, devoid of antibiotic properties, were developed and one of these, ABT229, was studied in large clinical trials. ${ }^{20}{ }^{21}$ However, the outcomes of clinical trials with ABT-229 were unequivocally disappointing with regard to symptom improvement, both in dyspeptics with delayed emptying and in patients with diabetic gastropathy and delayed emptying.
It has been argued that the negative outcomes of the studies with ABT-229 demonstrate that acceleration of gastric emptying is not the correct therapeutic target in functional dyspepsia. ${ }^{20}{ }^{21}$ However, there is a strong risk of tachyphylaxis with macrolide prokinetics, and especially with ABT-229. ${ }^{22-25}$ Hence, as measurement of gastric emptying was not repeated at the time of symptom assessment in the ABT229 studies, the relationship between changes in gastric emptying rate and changes in symptom severity in gastroparesis has remained unclear. ${ }^{22}$

The aim of the present study was to investigate the effect of a strong prokinetic on symptom severity in patients with gastroparesis. To overcome problems related to tachyphylaxis, the drug or placebo was administered acutely before a standardised meal and we quantified meal induced dyspeptic symptoms.

\section{MATERIALS AND METHODS \\ Study subjects}

Consecutive patients with functional dyspepsia were recruited for a validation study. Consecutive functional dyspepsia patients with previously established delayed gastric emptying were recruited for a pharmacological intervention study. Patients presented to the motility outpatient clinic because of symptoms suggestive of gastroparesis, and all underwent careful history taking and clinical examination, routine biochemistry, upper gastrointestinal endoscopy, upper abdominal ultrasound, and a gastric emptying breath test. $^{8} 122627$ In all patients with severely delayed emptying, a small bowel $x$ ray was also performed to rule out small bowel lesions or stenosis. Exclusion criteria were the presence of oesophagitis, gastric atrophy or erosive gastroduodenal lesions on endoscopy, the presence of lesions on small bowel 
$x$ ray, major abdominal surgery, underlying psychiatric illness, and the use of non-steroidal anti-inflammatory drugs, steroids, or drugs affecting gastric acid secretion.

Each patient completed a symptom questionnaire as reported previously. ${ }^{12} 2829$ The patient was asked to grade the intensity $(0-3 ; 0=$ absent, $1=$ mild, $2=$ relevant, and $3=$ severe, interfering with daily activities) of eight different symptoms (epigastric pain, bloating, postprandial fullness, early satiety, nausea, vomiting, belching, and epigastric burning) over the last three months. Also, the amount of weight lost since the onset of symptoms was noted.

All drugs potentially affecting gastrointestinal motility or sensitivity were discontinued at least one week prior to the gastric emptying studies. Informed consent was obtained from each participant. The protocol was previously approved by the ethics committee of the University Hospital.

\section{Gastric emptying breath test with assessment of meal related symptoms}

Gastric emptying rates for solids and liquids were determined using the ${ }^{14} \mathrm{C}$ octanoic acid and ${ }^{13} \mathrm{C}$ glycin breath test. ${ }^{812} 2627$ This test has previously been extensively validated. ${ }^{26}{ }^{27}$ The test meal consisted of $60 \mathrm{~g}$ of white bread, an egg, the yolk of which was doped with $74 \mathrm{kBq}$ of ${ }^{14} \mathrm{C}$ octanoid acid sodium salt (DuPont, NEN Research, Boston, Massachusetts, USA), and $300 \mathrm{ml}$ of water in which $100 \mathrm{mg}{ }^{13} \mathrm{C}$ glycin $(99 \%$ enrichment; Isotec, Miamisburg, Ohio, USA) was dissolved. All meals were consumed within a five minute period. The total caloric value of the test meal was $250 \mathrm{kcal}$. Breath samples were taken before the meal and at 15 minute intervals for a period of 240 minutes postprandially. At each sampling point, the subject exhaled into two different containers for measuring exhaled ${ }^{13} \mathrm{C}$ and ${ }^{14} \mathrm{C}$, respectively. One was a liquid scintillation vial containing $2 \mathrm{ml}$ of $\mathrm{l} \mathrm{M}$ hyamine hydroxide and $2 \mathrm{ml}$ of ethanol together with 1 drop of thymolphtalein solution. This amount of hyamine is neutralised by $2 \mathrm{mM} \mathrm{CO}$. The end point of neutralisation is indicated by decolouration of the indicator. After decolouration, $10 \mathrm{ml}$ of scintillation cocktail (Hionic Fluor; Packard Instrument Co., Downers Grove, Illinois, USA) was added and radiation was determined by liquid scintillation spectrometry (Packard Tri-Carb Liquid Scintillation Spectrometer, model 3375; Packard Instrument Co.). For ${ }^{13} \mathrm{C}$ measurements, breath was collected by blowing directly into a tube.

At each breath sampling, the patient was asked to grade the intensity $(0-3 ; 0=$ absent, $1=$ mild: present in a nonbothersome intensity, 2 =relevant: clearly present and bothersome but not of such intensity that it would interfere with normal daily activities, and $3=$ severe: clearly present and of such intensity that it would interfere with normal daily activities) of six different symptoms (epigastric pain, bloating, postprandial fullness, nausea, belching, and epigastric burning). We have previously shown that this questionnaire, when used over a time period of one week, shows excellent reproducibility. ${ }^{28}$ In the present study, we used this questionnaire, limited to regular postprandially occurring symptoms, and assessing only the period since the last breath sample.

\section{Reproducibility of gastric emptying and meal related symptoms}

To assess the reproducibility of the gastric emptying test with meal related symptoms, 20 patients underwent two gastric emptying breath tests with assessment of meal related symptoms, approximately two months apart. All drugs potentially affecting gastrointestinal motility or sensitivity were discontinued at least one week prior to the gastric emptying studies.

\section{Studies on the influence of erythromycin on gastric} emptying and meal related symptoms

To assess the influence of erythromycin, 24 patients underwent two gastric emptying breath tests with assessment of meal related symptoms, approximately one months apart. All drugs potentially affecting gastrointestinal motility or sensitivity were discontinued at least one week prior to the gastric emptying studies. At the start of the meal, saline or erythromycin $200 \mathrm{mg}$ were infused intravenously over 20 minutes in a double blind, randomised, crossover design. The order of saline and erythromycin treatment was randomised by drawing cards from a box of cards determining the sequence. A study nurse who was otherwise not involved in the study administered the medication. Half of the subjects received saline first; the other half received erythromycin first.

\section{Data analysis}

Symptom scores were obtained before and for four hours after the standardised meal. For each symptom, a meal related severity score was obtained by adding scores at all time points. A cumulative meal related symptom score was obtained by adding individual symptom severity scores.

The ${ }^{13} \mathrm{C}$ breath content was determined by online gas chromatographic purification-isotope ratio mass spectrometry (ABCA; Europe Scientific, Crewe, UK). For both carbon labels, $\mathrm{CO}_{2}$ production was assumed to be $300 \mathrm{mmol} / \mathrm{m}^{2}$ of body surface per hour. Body surface area was calculated by the weight-height formula of Haycock and colleagues. ${ }^{7}$ The results of the ${ }^{13} \mathrm{CO}_{2}$ and ${ }^{14} \mathrm{CO}_{2}$ breath tests were expressed as percentage ${ }^{13} \mathrm{CO}_{2}$ and ${ }^{14} \mathrm{CO}_{2}$, respectively, excreted per hour by calculating procedures described elsewhere. ${ }^{6}{ }^{14}$ Gastric half emptying time $\left(\mathrm{t}_{1 / 2}\right)$ was calculated from ${ }^{13} \mathrm{CO}_{2}$ and ${ }^{14} \mathrm{CO}_{2}$ content of breath samples, as previously described. ${ }^{8}{ }^{12} 2627$

\section{Statistical analysis}

Results are expressed as mean (SEM). The Student's $t$ test was used to compare results on different days or after different pretreatments. A p value $<0.05$ was considered significant. The reproducibility of measurements was evaluated by comparing results between the two sessions by paired two tailed $t$ test and by linear correlation analysis where indicated. Bonferroni's correction for multiple comparisons was applied.

The variability of the test was quantified by calculating the individual coefficient of variation expressed as per cent $(\mathrm{CV}=\mathrm{SD}$ of the difference between both measurements, divided by the mean value, and expressed as a percentage). Based on the variability of the test results, the erythromycin study was estimated to have more than $80 \%$ power to detect $35 \%$ changes in symptom scores at a 0.05 significance level.

\section{RESULTS}

\section{Patient characteristics}

Forty four patients ( 37 women, seven men; aged $17-70$ years (mean 43.1 (2.1)) with longstanding dyspeptic symptoms were recruited into the study. Previous studies had established a mean half emptying time for solids of 123 (16) minutes and for liquids 78 (4) minutes. Table 1 summarises the grading of dyspeptic symptoms in the patient group. Postprandial fullness and bloating were the most prevalent symptoms, present in $86 \%$ and $84 \%$ of patients, respectively. Epigastric pain (77\%), early satiety $(66 \%)$, nausea $(70 \%)$, and belching $(68 \%)$ were also frequently reported. Vomiting and epigastric burning sensations were present in $39 \%$ and $64 \%$ of patients, respectively. Weight loss in excess of $5 \%$ was present in 22 patients $(50 \%)$. Seven patients $(16 \%)$ had Helicobacter pylori infection on gastric biopsies. 
Table 1 Frequency of severity grading for each of eight dyspepsia symptoms in 44 patients with functional dyspepsia

\begin{tabular}{lcccc}
\hline & 0 (absent) & $\mathbf{1}$ (mild) & 2 (relevant) & $\mathbf{3}$ (severe) \\
\hline Postprandial fullness & $6(14)$ & $3(7)$ & $17(39)$ & $18(41)$ \\
Bloating & $7(16)$ & $5(11)$ & $19(43)$ & $13(30)$ \\
Epigastric pain & $10(23)$ & $7(16)$ & $13(30)$ & $14(32)$ \\
Early satiety & $15(34)$ & $6(14)$ & $8(18)$ & $15(34)$ \\
Nausea & $13(30)$ & $11(25)$ & $8(18)$ & $12(27)$ \\
Vomiting & $27(61)$ & $6(14)$ & $4(9)$ & $7(16)$ \\
Belching & $14(32)$ & $11(25)$ & $14(32)$ & $5(11)$ \\
Epigastric burning & $16(36)$ & $9(20)$ & $13(30)$ & $6(14)$ \\
\hline \multicolumn{5}{l}{ Values are numbers (row percentages). } \\
\end{tabular}

\section{Reproducibility of gastric emptying and meal related symptoms}

Twenty patients (16 women and four men; mean age 42.6 (2.6) years, body mass index $21.1(1.2) \mathrm{kg} / \mathrm{m}^{2}$ ) with longstanding dyspeptic symptoms were recruited for this part of the study. During the first gastric emptying breath test, half emptying times for solids and liquids were 94.7 (12.6) and 67.3 (5.2) minutes, respectively. During the first test, five patients had delayed emptying for solids $\left(\mathrm{t}_{1 / 2}>109\right.$ minutes $)$ compared with previously established normal values. ${ }^{8}$ The second emptying test confirmed delayed emptying in only three of these, and three other patients with previously normal emptying were also delayed. Meal related symptom severity scores are summarised in table 2. The highest symptom severity scores were obtained for bloating and fullness, while epigastric burning was less prominent. No significant correlation was found between cumulative or individual meal related symptom scores and solid or liquid emptying times.

The gastric emptying test with meal related symptoms was repeated 63 (7) days later. The results and reproducibility are summarised in fig 1 and table 2. Emptying times, meal related symptom severity scores, and cumulative symptom severity scores did not differ significantly and were significantly correlated (all $r$ values $>0.58$; all $\mathrm{p}$ values $<0.01$ ). The best reproducibility and lowest variability were found for the cumulative symptom score and meal related scores for fullness, bloating, and pain. As illustrated in fig $1 \mathrm{~B}$, the evolution of symptom severity during the four hour postprandial time window also showed excellent reproducibility. Solid and liquid emptying times showed the greatest variability (table 2 ).

Table 2 Reproducibility of gastric emptying and meal related symptom scores in 20 patients with functional dyspepsia

\begin{tabular}{lccl}
\hline & $\begin{array}{l}\text { 1st emptying } \\
\text { test }\end{array}$ & $\begin{array}{l}\text { 2nd emptying } \\
\text { test }\end{array}$ & CV (\%) \\
\hline Solid $t_{1 / 2}(\mathrm{~min})$ & $86(7)$ & $90(7)$ & 73 \\
${\text { Liquid } t_{1 / 2}(\mathrm{~min})}_{\text {Cumulative symptom score }}$ & $67(5)$ & $69(5)$ & 67 \\
Fullness & $28(16)$ & $116(19)$ & 48 \\
Bloating & $25(5)$ & $27(5)$ & 59 \\
Belching & $21(3)$ & $25(5)$ & 30 \\
Nausea & $17(4)$ & $18(4)$ & 49 \\
Epigastric pain & $15(4)$ & $18(5)$ & 41 \\
Epigastric burning & $7(3)$ & $8(4)$ & 40 \\
\hline
\end{tabular}

Half emptying times $\left(t_{1 / 2}\right)$ and symptom severity scores for repeated testing are shown, as well as the coefficient of variability (CV\%) between the results of both tests.

\section{Influence of erythromycin on gastric emptying and meal related symptoms}

Twenty four patients (21 women and three men; mean age 43.5 (3.2) years, body mass index $\left.22.2(0.8) \mathrm{kg} / \mathrm{m}^{2}\right)$ with longstanding dyspeptic symptoms and previously established delayed gastric emptying were recruited for this part of the study. They underwent two gastric emptying tests with administration of saline or erythromycin on average 26 (8) days apart. After administration of saline, both solid and liquid gastric emptying were clearly delayed ( $t_{1 / 2} 146$ (27) and 87 (6) minutes, respectively), as expected on the basis of selection of patients. The cumulative and individual meal related symptom severity scores are summarised in fig 2 .

After administration of erythromycin, both solid and liquid gastric emptying times were significantly enhanced $\left(t_{1 / 2} 72\right.$ (7) and 63 (5) minutes, respectively; both $p<0.01$ compared with saline). However, the cumulative meal related symptom score was not altered by pretreatment with erythromycin (fig 2A). Similarly, except for bloating, none of the individual symptom severity scores improved after administration of erythromycin (figs 2, 3).

No significant correlation was found between changes in cumulative or individual meal related symptom scores and changes in solid half emptying times.
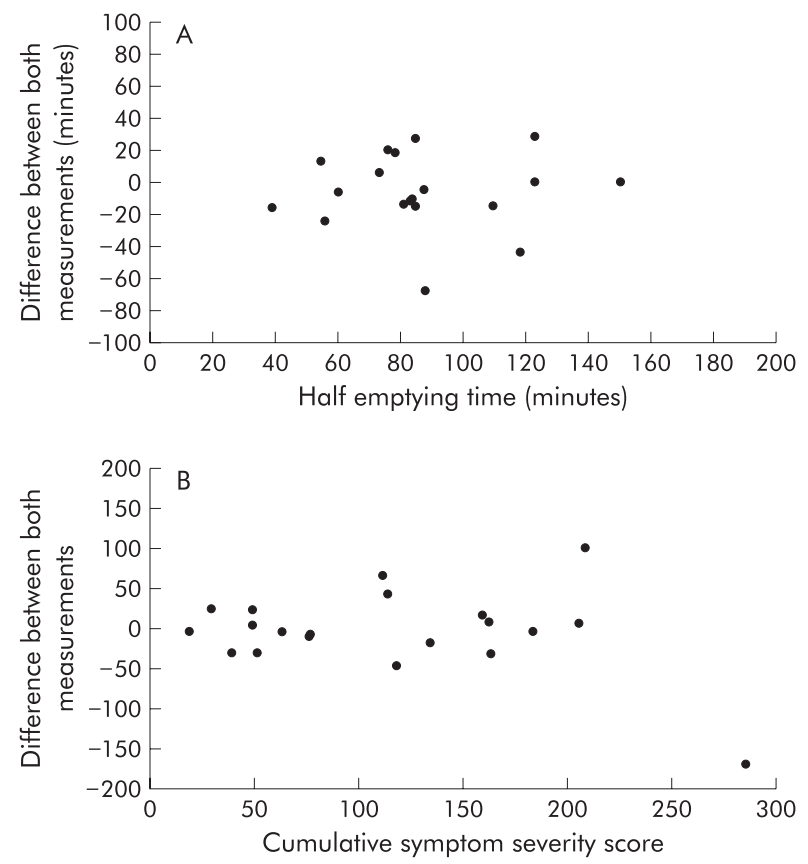

Figure 1 Bland-Altman plots depicting the reproducibility of solid half emptying times (A) and meal related symptoms (B) when patients were tested twice with a two month interval. 

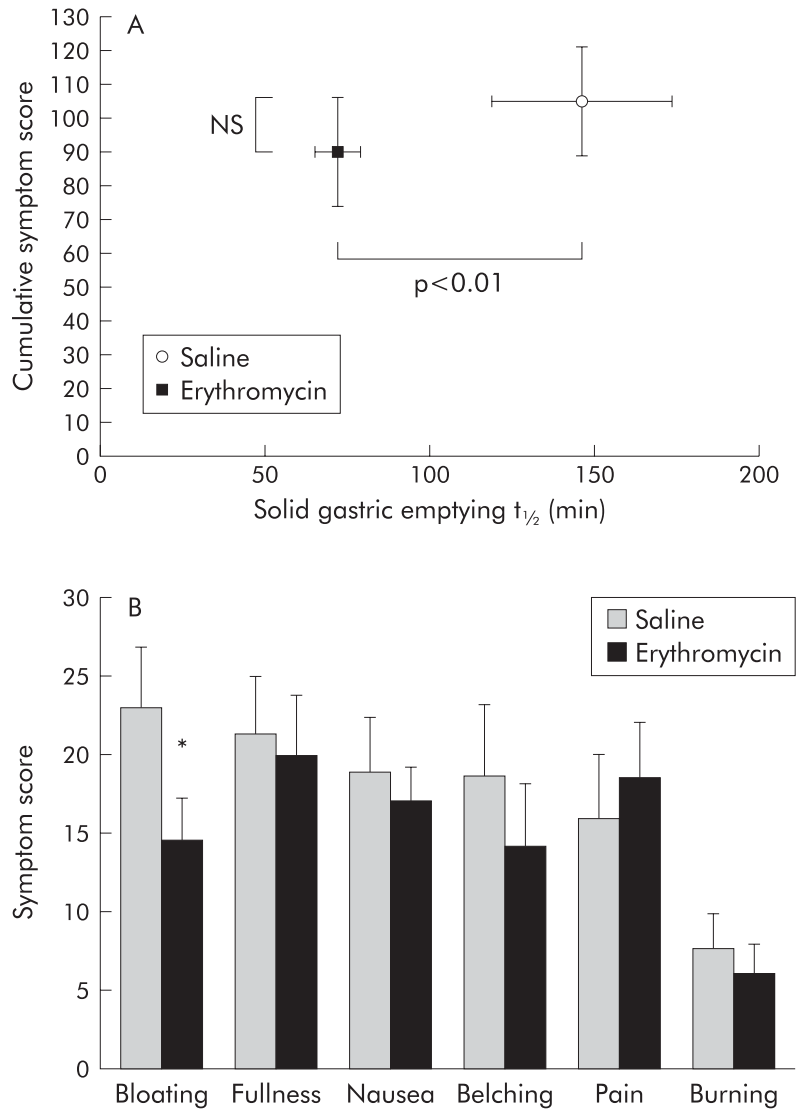

Figure 2 Influence of erythromycin $200 \mathrm{mg}$ intravenously on gastric emptying rate and meal related symptom testing in 24 patients with functional dyspepsia and delayed gastric emptying. (A) Treatment with erythromycin enhanced solid gastric emptying rate but did not influence cumulative meal related symptom severity. (B) Erythromycin induced a significant decrease in the severity of meal related bloating but did not affect any of the other meal related symptoms ( ${ }^{*} p<0.05 v$ placebo).

\section{DISCUSSION}

Traditionally, prokinetic agents, including metoclopramide, domperidone, and cisapride, have been widely used in the treatment of functional dyspepsia. ${ }^{13-15}$ Although recent systematic analyses reported that prokinetics were more effective than placebo, trials were often of poor quality and a significant heterogeneity between studies was present. ${ }^{30}{ }^{31}$ It is now evident that only a subset of patients with functional dyspepsia have delayed gastric emptying. ${ }^{6-12}$ As it seems logical to direct pharmacotherapeutic approaches towards the underlying pathophysiological disturbance, gastroprokinetic drugs are most likely to be beneficial to patients with delayed gastric emptying, and they should improve the associated symptoms of postprandial fullness, nausea, and vomiting. ${ }^{10-12} 32$ However, these prokinetic drugs also affect other putative pathophysiological mechanisms in functional dyspepsia, ${ }^{33}{ }^{34}$ and evidence from studies with prokinetics that their effect is related to enhancement of gastric emptying is lacking. ${ }^{1}{ }^{2} 3$

Erythromycin, a macrolide antibiotic, was the first compound of a new class of gastroprokinetics that act through agonism at the motilin receptor on nerves and smooth muscle in the stomach. ${ }^{17} 36{ }^{37}$ Compared with previously existing prokinetics, erythromycin has stronger effects on gastric motility, ${ }^{15}$ and several motilin agonists lacking antibiotic activity were developed. One of them, ABT-229, was evaluated in large controlled studies but no favourable effect was observed in patients or in those with established
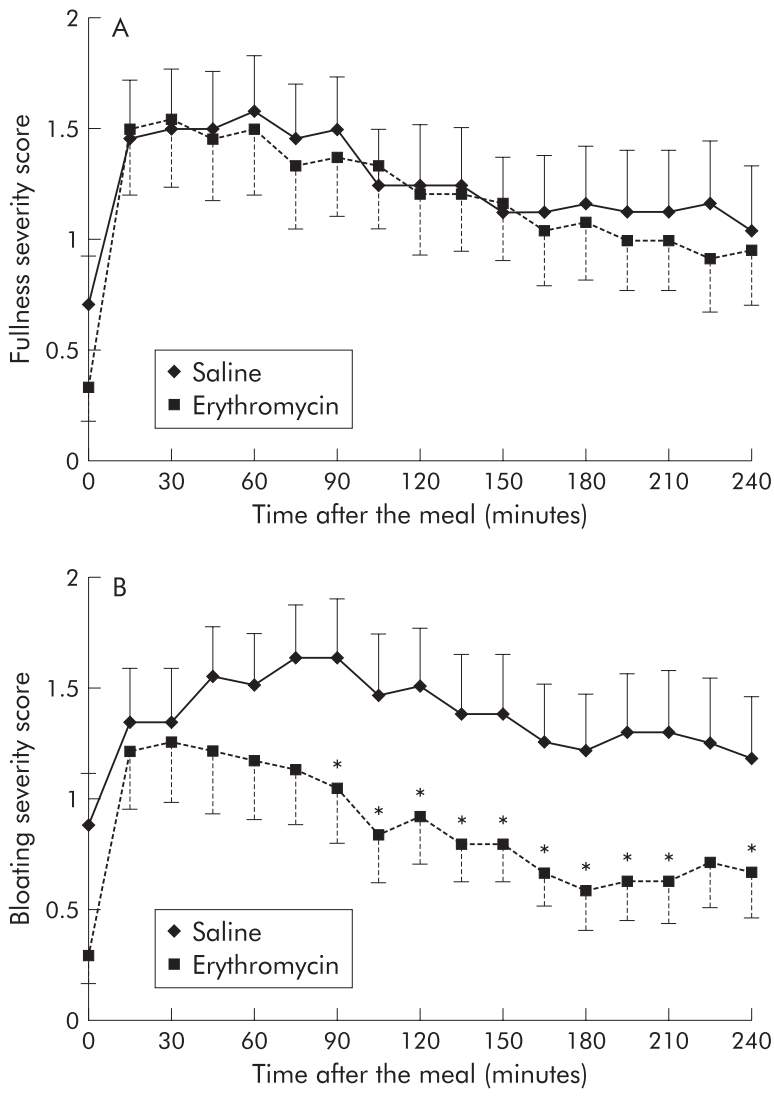

Figure 3 Influence of erythromycin $200 \mathrm{mg}$ intravenously on the severity of meal related symptoms and their evolution in a four hour postprandial window. (A) Treatment with erythromycin did not alter the severity of fullness or its evolution in a four hour postprandial window. (B) Treatment with erythromycin significantly decreased the severity of bloating in a four hour postprandial time window $\left({ }^{*} p<0.05 v\right.$ placebo at this time point).

delayed gastric emptying. ${ }^{20}{ }^{21}$ Based on the negative outcome of the ABT-229 studies, it was suggested that enhancing gastric emptying was not a useful target in the treatment of dyspeptic symptoms. However, the reasons for the negative results are unclear, and apart from interference of the drug with gastric accommodation, desensitisation of the motilin receptor was also suggested as a possible explanation. ${ }^{22}$

In the present study, we evaluated the symptomatic effect of a motilin receptor agonist during acute administration, thereby avoiding interference from receptor desensitisation. Firstly, we established that gastric emptying with meal related symptom assessment was reproducible in functional dyspepsia. The observation that quantification of meal related symptoms had a better reproducibility than gastric emptying time not only confirmed the validity of using a meal as a provocative test in functional dyspepsia but also illustrated the variability of gastric emptying rates in dyspeptic patients, at least with the breath test used in patients in the present study. It has been reported that scintigraphic gastric emptying has a smaller intra-subject variability in healthy controls. $^{38}$ There was no significant relationship between gastric emptying rate and any of the dyspeptic symptoms. This is in apparent contrast with an earlier study which reported an association between delayed emptying and symptoms of nausea, vomiting, and postprandial fullness. ${ }^{12}$ However, the latter study involved 395 subjects, and the present study was not powered to establish such correlations.

Subsequently, we used this test to evaluate the influence of erythromycin on symptoms and gastric emptying rate. In line 
with previous studies, ${ }^{15}{ }^{17-19}$ we confirmed that acute administration of erythromycin significantly enhanced gastric emptying of both solids and liquids. We confirmed some therapeutic potential of prokinetic treatment, as we observed significant improvement in bloating after administration of erythromycin compared with placebo. The improvement in bloating scores was not significantly correlated with changes in gastric half emptying time, but other aspects of prokinetic activity such as intragastric distribution, lag time, and emptying rates over time after the meal were not assessed. Furthermore, it remains to be established whether this decrease in bloating severity of approximately $35 \%$ is clinically meaningful. However, the study also confirmed the limitations of the therapeutic potential of this class of prokinetics, as other symptoms, as well as cumulative meal related symptoms, were not improved by erythromycin.

The symptoms of postprandial fullness and nausea, associated with delayed gastric emptying in a number of studies, ${ }^{10-12}$ were not influenced by erythromycin treatment, which significantly enhanced the gastric emptying rate. These observations suggest that there is no direct relationship between delayed gastric emptying and the severity of these symptoms. It is conceivable that a hitherto unclarified mechanism induces both delayed emptying and symptoms of fullness, nausea, and vomiting. On the other hand, it is conceivable that improvement of certain symptoms, unrelated to enhanced gastric emptying, would require prolonged exposure to prokinetics, and the inability to detect such influences is a clear limitation of the present study design. The findings of this study cannot be extrapolated to prokinetics that do not act through the motilin receptor. It is well established that erythromycin and related compounds impair gastric accommodation to a meal, ${ }^{39}{ }^{40}$ thereby enhancing sensitivity to gastric distension, ${ }^{41}$ which may have contributed to the overall poor symptomatic effect. The prokinetic 5 -hydroxytryptamine- 4 receptor agonists cisapride and tegaserod were shown to enhance gastric accommodation to a meal ${ }^{34}$ and are therefore less likely to worsen or induce symptoms related to impaired accommodation. If the lack of overall symptomatic effect of erythromycin is related to its effect on the proximal stomach, more selective motilin receptor agonists that are devoid of an effect on the proximal stomach might be useful. Both in vitro and in vivo studies have shown that erythromycin can activate motilin receptors on gastric smooth muscle and on intrinsic cholinergic nerves..$^{3744}$ In human and rabbit antrum, the effects of lower doses of erythromycin are neurally mediated whereas higher doses induce direct muscular effects. ${ }^{37}{ }^{44}$ As the effects of motilin receptor activation on the proximal stomach are direct smooth muscle effects, ${ }^{40}$ motilin receptor agonists with selectivity for the putative neural receptors might have a better symptomatic effect.

In summary, we have shown that acute administration of erythromycin in patients with functional dyspepsia and delayed gastric emptying enhances gastric emptying and improves meal induced bloating. Other dyspeptic symptoms, including postprandial fullness and nausea, were not significantly altered by erythromycin, and the cumulative meal related symptom severity score was not improved. These findings suggest that the therapeutic effect of currently available motilin receptor agonists in the treatment of functional dyspepsia is at best modest.

\section{Authors' affiliations}

J Arts, P Caenepeel, K Verbeke, J Tack, Department of Gastroenterology, University Hospitals Leuven, Belgium

Conflict of interest: None declared.

\section{REFERENCES}

1 Corinaldesi R, Stanghellini V, Raiti C, et al. Effect of chronic administration of cisapride on gastric emptying of a solid meal and on dyspeptic symptoms in patients with idiopathic gastroparesis. Gut 1987;28:300-5.

2 Jian R, Ducrot F, Ruskone A, et al. Symptomatic, radionuclide and therapeutic assessment of chronic idiopathic dyspepsia. A double-blind placebocontrolled evaluation of cisapride. Dig Dis Sci 1989;34:657-64.

3 Talley NJ, Shuter B, McCrudden G, et al. Lack of association between gastric emptying of solids and symptoms in nonulcer dyspepsia. J Clin Gastroenterol $1989 ; 11: 625-30$

4 Scott AM, Kellow JE, Shuter B, et al. Intragastric distribution and gastric emptying of solids and liquids in functional dyspepsia. Lack of influence of symptom subgroups and $\mathrm{H}$. pylori-associated gastritis. Dig Dis Sci 1993;38:2247-54.

5 Bortolotti M, Bolondi L, Santi V, et al. Patterns of gastric emptying in dysmotility-like dyspepsia. Scand J Gastroenterol 1995;30:408-10.

6 Koskenpato J, Kairemo K, Korppi-Tommola T, et al. Role of gastric emptying in functional dyspepsia: a scintigraphic study of 94 subjects. Dig Dis Sci 1998:43:1154-8.

7 Quartero AO, de Wit NJ, Lodder AC, et al. Disturbed solid-phase gastric emptying in functional dyspepsia: a meta-analysis. Dig Dis $\mathrm{Sci}$ 1998:43:2028-33.

8 Maes BD, Ghoos YF, Hiele MI, et al. Gastric emptying rate of solids in patients with nonulcer dyspepsia. Dig Dis Sci 1997;42:1158-62.

9 Talley NJ, Verlinden M, Jones M. Can symptoms discriminate among those with delayed or normal gastric emptying in dysmotility-like dyspepsia? Am J Gastroenterol 2001;96:1422-8.

10 Stanghellini V, Tosetti C, Paternico A, et al. Risk indicators of delayed gastric emptying of solids in patients with functional dyspepsia. Gastroenterology 1996; 110:1036-42.

11 Perri F, Clemente R, Festa V, et al. Patterns of symptoms in functional dyspepsia: Role of Helicobacter pylori infection and delayed gastric emptying. Am J Gastroenterol 1998;93:2082-8.

12 Sarnelli G, Caenepeel P, Geypens B, et al. Symptoms associated with impaired gastric emptying of solids and liquids in functional dyspepsia. Am J Gastroenterol, 98:783-8.

13 Holtmann G, Talley NJ. Functional dyspepsia. Current treatment recommendations. Drugs 1993;45:918-30.

14 Finney JS, Kinnersley N, Hughes M, et al. Meta-analysis of antisecretory and gastrokinetic compounds in functional dyspepsia. J Clin Gastroenterol 1998;26:312-20

15 Sturm A, Holtmann G, Goebell H, et al. Prokinetics in patients with gastroparesis: a systematic analysis. Digestion 1999:60:422-7.

16 Tack J, Bisschops R, DeMarchi B. Causes and treatment of functional dyspepsia. Curr Gastroenterol Rep 2001;3:503-8.

17 Janssens J, Peeters TL, Vantrappen G, et al. Improvement of gastric emptying in diabetic gastroparesis by erythromycin. N Engl J Med 1990;332:1028-31.

18 Richards RD, Davenport K, McCallum RW. The treatment of idiopathic and diabetic gastroparesis with acute intravenous and chronic oral erythromycin. Am J Gastroenterol 1993;88:203-7.

19 DiBaise JK, Quigley EM. Efficacy of prolonged administration of intravenous erythromycin in an ambulatory setting as treatment of severe gastroparesis: one center's experience. J Clin Gastroenterol 1999;28:131-4.

20 Talley NJ, Verlinden M, Snape W, et al. Failure of a motilin receptor agonist (ABT-229) to relieve the symptoms of functional dyspepsia in patients with and without delayed gastric emptying: a randomized double-blind placebocontrolled trial. Aliment Pharmacol Ther 2000;14:1653-61.

21 Talley NJ, Verlinden M, Geenen DJ, et al. Effects of a motilin receptor agonist (ABT-229) on upper gastrointestinal symptoms in type 1 diabetes mellitus: a randomised, double blind, placebo controlled trial. Gut 2001;49:395-401.

22 Tack J, Peeters. What comes after macrolides and other motilin stimulants? Gut 2001;49:317-8.

23 Verhagen MA, Samsom M, Maes B, et al. Effects of a new motilide, ABT-229, on gastric emptying and postprandial antroduodenal motility in healthy volunteers. Aliment Pharmacol Ther 1997;11:1077-86.

24 Thielemans L, Perret J, Depoortere I, et al. Differences in the ability of motilides to induce motilin receptor internalization underly their desensitising capacity. Gastroenterology 2003; 124:A1.

25 Bologna SD, Hasler WL, Owyang C. Down-regulqtion of motilin receptors on rabbit colon myocytes by chronic oral erythromycin. J Pharmacol Exp Ther 1993;266:852-6

26 Ghoos YF, Maes BD, Geypens BJ, et al. Measurement of gastric emptying rate of solids by means of a carbon labeled octanoic acid breath test. Gastroenterology 1993;104:1640-7.

27 Maes BD, Ghoos YF, Geypens BJ, et al. Combined carbon-13-glycin/carbon14-octanoic acid breath test to monitor gastric emptying rates of liquids and solids. J Nucl Med 1994;35:824-31.

28 Tack J, Piessevaux H, Coulie B, et al. Role of impaired gastric accommodation to a meal in functional dyspepsia. Gastroenterology 1998;1 15:1346-52.

29 Tack J, Caenepeel P, Fischler B, et al. Hypersensitivity to gastric distention is associated with symptoms in functional dyspepsia. Gastroenterology $2001 ; 121: 526-35$

30 Soo S, Moayyedi P, Deeks J, et al. Pharmacological interventions for non-ulcer dyspepsia. Cochrane Database Syst Rev 2000;2:CD001960.

31 Veldhuyzen van Zanten SJ, Jones MJ, Verlinden $M$, et al. Efficacy of cisapride and domperidone in functional (nonulcer) dyspepsia: a meta-analysis. Am J Gastroenterol 2001;96:689-96.

32 Talley NJ. Functional dyspepsia: Should treatment be targeted on disturbed physiology? Aliment Pharmacol Ther 1995;9:107-15. 
33 Bradette $M$, Pare $P$, Douville $P$, et al. Visceral perception in health and functional dyspepsia. Crossover study of gastric distension with placebo and domperidone. Dig Dis Sci 1991;36:52-8.

34 Tack J, Broeckaert D, Coulie B, et al. The influence of cisapride on gastric tone and the perception of gastric distension. Aliment Pharmacol Ther 1998; 12:761-6.

35 Kellow JE, Cowan H, Shuter B, et al. Efficacy of cisapride therapy in functional dyspepsia. Aliment Pharmacol Ther 1995;9:153-60.

36 Peeters TL, Matthijs G, Depoortere I, et al. Erythromycin is a motilin receptor agonist. Am J Physiol 1989;237:G470-4.

37 Kong MF, Perkins AC, King P, et al. Reproducibility of gastric emptying of a pancake and milkshake meal in normal subjects. Nucl Med Commun 1998; 19:77-82.

38 Coulie B, Tack J, Janssens J. Involvement of two different pathways in the motor effects of erythromycin on the gastric antrum in man. Gut 1998;43:395-400
39 Bruley des Varannes S, Parys V, Ropert A, et al. Erythromycin enhances fasting and postprandial proximal gastric tone in humans. Gastroenterology 1995; 109:32-9.

40 Cuomo R, Tack J, Vandaele P, et al. Influence of motilin on gastric fundus tone and on meal-induced satiety in man (submitted).

41 Piessevaux H, Tack J, Wilmer A, et al. Perception of changes in wall tension of the proximal stomach in man. Gut 2001;49:203-8.

42 Tack J, Vos R, Janssens J, et al. Influence of tegaserod on proximal gastric tone and on the perception of gastric distention. Aliment Pharmacol Ther 2003; 18:1-7.

43 Poitras $\mathbf{P}$, Miller P, Dickner $M$, et al. Heterogeneity of motilin receptors in the gastrointestinal tract of the rabbit. Peptides 1996;17:701-7.

44 Van Assche G, Depoortere I, Thijs T, et al. Concentration-dependent stimulation of cholinergic motor nerves or smooth muscle by motilin in the isolated rabbit gastric antrum. Eur J Pharmacol 1997;337:267-74.

\section{EDITOR'S QUIZ: GI SNAPSHOT}

\section{An unusual cause of abdominal pain in a patient with hepatitis $C$ cirrhosis}

Robin Spiller, Editor

A 51 year man with a history of hepatitis C cirrhosis presented with a two day history of fever, malaise, abdominal distension, and severe abdominal pain in his right upper quadrant. On examination he had significant tenderness and guarding in his right upper quadrant. A computed tomography scan revealed a nodular and cirrhotic liver, moderate ascites, and enlarged spleen (fig 1A). There was air within the superior mesenteric veins (arrows) along with marked bowel wall thickening at the hepatic flexure and pneumatosis (arrowheads) suggesting necrotic bowel (fig 1A). He was taken to the operating room for an exploratory laparotomy that revealed a severely inflamed, enlarged, and indurated right hemicolon, without perforation. Right hemicolectomy with an end to end ileocolic anastomosis was successfully performed. The histology of the resected specimen is displayed in fig $1 \mathrm{~B}$.

\section{Question}

What is the diagnosis?

See page 521 for answer

This case is submitted by:

A Cárdenas, $\mathrm{N}$ H Afdhal

Liver Center, Department of Gastroenterology and Hepatology, Beth Israe Deaconess Medical Center and Harvard Medical School, Boston, USA

K Khwaja

Department of Hepatobiliary Surgery and Liver Transplantation, Beth Israe Deaconess Medical Center, Harvard Medical School, Boston, USA

Correspondence to: Dr A Cardenas, Division of Gastroenterology and Hepatology, Beth Israel Deaconess Medical Center, Harvard Medical School, 110 Francis St Ste 8E, Boston, MA 02215, USA; acardena@bidmc.harvard.edu

doi: 10.1136/gut.2004.049122
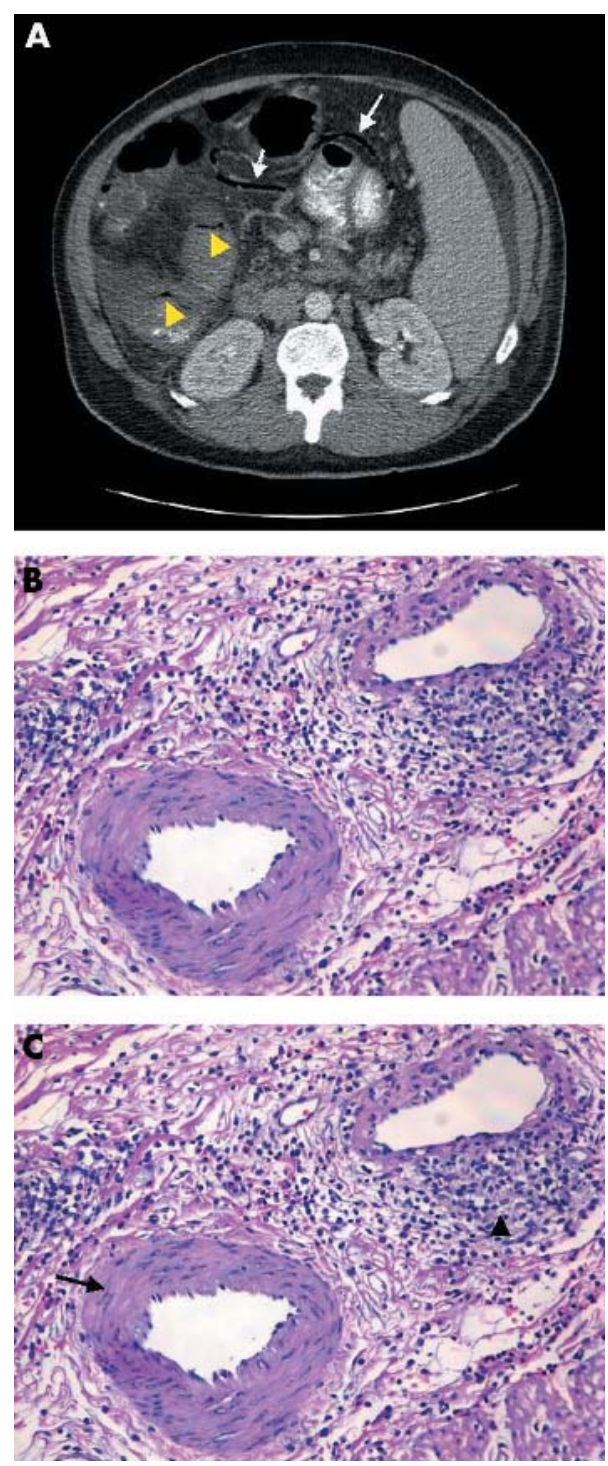

Figure 1 Computed tomography scan of the liver revealing a nodular and cirrhotic liver, moderate ascites, and enlarged spleen (A). There was air within the superior mesenteric veins (arrows) along with marked bowel wall thickening at the hepatic flexure and pneumatosis (arrowheads). (B, C) Histology of resected specimens. 